\title{
Las derivas del pensar cinematográfico como provocaciones para la enseñanza de la filosofía
}

Laura Galazzi ${ }^{10}$

Universidad de Buenos Aires/ Universidad Nacional de Luján, Argentina

Autor de correspondencia: 'lgalazzi@filo.uba.ar Recibido: 21 de agosto de 2020 Revisado: 18 de septiembre de 2020 Aprobado: 18 de enero de 2021 Publicado: 8 de abril de 2021

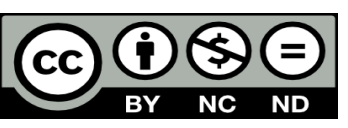

\section{Resumen}

En este artículo se considera al cine como una forma de pensamiento. Se exploran tres modalidades del pensar cinematográfico basadas en clasificaciones teóricas generales surgidas en los estudios cinematográficos, con el propósito de desarrollar posibles aportes a la enseñanza de la filosofía. La primera se funda en el cine clásico y se conecta con una perspectiva instrumental del uso del cine en la enseñanza, que apunta a potenciar habilidades lógico-racionales o a ser una herramienta crítica de la razón instrumental. La segunda modalidad corresponde a las exploraciones propias del cine moderno. Se vincula este pensar con las modalidades de trabajo en enseñanza de la filosofía, que apuntan a realizar experiencias abiertas a los afectos, los cuerpos y otras perspectivas propias de exploraciones pedagógico-filosóficas contemporáneas. Finalmente se propone, a partir del cine digital, incorporar la realización de audiovisuales como una modalidad de trabajo en el aula de filosofía. Se desarrollan los fundamentos estético-políticos de esa necesidad y se hace referencia al tipo de circulación que tienen las imágenes en la cultura contemporánea. Luego se sistematiza la experiencia de un taller de realización de videominutos en el que se trabajó desde esa perspectiva.

Palabras clave: cine, enseñanza de la filosofía, enseñanza audiovisual, educación, pensamiento

Para citar este artículo: Galazzi, L. (2021). Las derivas del pensar cinematográfico como provocaciones para la enseñanza de la filosofía. Praxis \& Saber, 12(29), e11607. https://doi. org/10.19053/22160159.v12.n29.2021.11607 


\title{
The drifts of cinematic thinking as stimuli for the teaching of philosophy
}

\begin{abstract}
In this article, film is considered as a way of thinking. Three modes of cinematic thinking are explored, based on general theoretical classifications emerging in film studies, with the aim of elaborating possible contributions to the teaching of philosophy. The first is based on classical cinema and is connected to an instrumental perspective on the use of film in education, which aims to enhance logical-rational skills or to be a critical tool of instrumental rationality. The second mode refers to the explorations of modern cinema. This thinking is connected to the ways of working in philosophy teaching, which is open to affects, bodies and other perspectives of contemporary pedagogical-philosophical explorations. Finally, it is proposed, based on digital cinema, to incorporate the production of audiovisuals as a way of working in the philosophy classroom. The aesthetic-political foundations of this need are developed and the kind of consumption of images in contemporary culture is discussed. Then, the experience of a workshop on the production of one-minute films in which we worked from this perspective is documented.
\end{abstract}

Keywords: cinema, philosophy teaching, audio-visual teaching, education, thinking

\section{As derivas do pensamento cinematográfico como estímulo para o ensino da filosofia}

\section{Resumo}

Neste artigo, o cinema é considerado como uma forma de pensar. Três modalidades de pensamento cinematográfico são exploradas, com base nas classificações teóricas gerais que surgem nos estudos cinematográficos, com o objetivo de elaborar possíveis contribuições para o ensino da filosofia. O primeiro baseia-se no cinema clássico e está ligado a uma perspectiva instrumental sobre o uso do cinema na educação, que visa melhorar as habilidades lógico-racionais ou ser uma ferramenta crítica de racionalidade instrumental. A segunda modalidade se refere às explorações do cinema moderno. Este pensamento está ligado às modalidades de trabalho no ensino da filosofia, que está aberto a afetos, corpos e outras perspectivas das explorações pedagógico-filosóficas contemporâneas. Finalmente, propõe-se, com base no cinema digital, incorporar a produção de produtos audiovisuais como uma modalidade de trabalho na sala de aula de filosofia. Os fundamentos estéticopolíticos desta necessidade são desenvolvidos e o tipo de consumo de imagens na cultura contemporânea é discutido. Em seguida, a experiência de uma oficina sobre a produção de filmes de um minuto em que trabalhamos a partir desta perspectiva é documentada.

Palavras-chave: cinema, ensino de filosofia, ensino audiovisual, educação, pensamento 
${ }^{1}$ Una de las provocaciones deleuzianas respecto del cine que más me gustan consiste en su afirmación del cine como un pensar (Deleuze, 1986). No como un modo del pensar humano, no como una variación o una prótesis - una extensión del pensamiento tal como lo conocíamos-, sino como un pensar a secas, un pensar que se podría vincular con un percibir, con un meditar, un reflexionar, y con todas las distintas modalidades que le atribuimos al pensamiento, pero que no se centra en un yo - ya sea el artista, espectador o pensadoraque da sentido y cristaliza la acción. Un pensar maquínico, inorgánico, regido por un sistema de dispositivos en que los humanos somos conectores, catalizadores, componentes de una metafísica del mirar, del reconstituir, del sintetizar y del inventar, en que perceptos ${ }^{2}$, afectos y conceptos se entrelazan para tejer sentidos que se proyectan fantasmalmente y despliegan una cognición inexistente hasta antes de la experiencia del cine.

Schwarzböck (2017) propone que, "a diferencia de la pregunta por cualquier otra de las artes, la pregunta por el cine excede a la estética. Es la pregunta que pone a la estética en relación con la política de masas, revolucionaria o reaccionaria" (p. 81). En este sentido, resulta fundamental interrogar al cine, porque hacerlo implica pensar sobre el arte, pero también preguntar por un tipo de pensamiento que articula el momento histórico en el que vivimos, el régimen político al que contribuimos, el mundo que conformamos.

Este extraño constructo ontológico que se abre con la existencia del cine es un desafío para la filosofía, en tanto tomemos seriamente su dimensión ligada a la pregunta y a la escucha de lo desconocido. El cine nos invita a un mundo por pensar, que puede resignificar los conceptos mismos de pensamiento y de mundo. Por ello, produjo tantos recaudos en su inicio, cuando rápidamente se lo quiso reducir a lo conocido. Algunos afirmaron que el cine era un atractivo de feria, pasajero, que no era novedad alguna, ya que solo era la suma de la fotografía, el teatro, la música y las artes ya conocidas, sin agregar nada por sí mismo. Sin embargo, está a la vista de todos que el cine triunfó. Como ningún otro arte, tuvo en los siglos XX y lo que va del XXI derivas inesperadas y mutaciones que lo hacen omnipresente en nuestras vidas cotidianas. Con el cine se reconfiguran nuevos lenguajes que van desde la televisión hasta la visión de 360 grados, la realidad virtual y la construcción de mundos digitales al alcance de un celular.

En este sentido, considerar al cine como un pensamiento que a su vez constituye una posibilidad abierta, sobre todo para revisar la configuración estético-política de lo real, permite indagar en el campo de la filosofía por preguntas que también hemos hecho sobre el pensamiento humano y, en este sentido, volver a plantearnos qué es el pensar del cine, cómo piensa, para qué piensa y quién piensa en él. En este artículo tomo la pregunta por el cómo, porque me permite ordenar la exposición y explorar tres tipos de consecuencia para la enseñanza de la filosofía. Me quedaré, además, en esta última disciplina para desarrollar una vía de trabajo con mucho potencial para la reflexión filosófica, como la realización de talleres de videominutos en las aulas de filosofía.

\footnotetext{
$1 \quad$ Una versión breve de la primera parte de este texto se presentó en la mesa "Cine, pensamiento y enseñanza” en el 3er Seminario Internacional "Filosofía y Enseñanza. Cine, Filosofía, Pensamiento", organizado el 13 y 14 de noviembre de 2019 por la UPTC y la Uniminuto.

2 Los perceptos, para Deleuze, pertenecen al dominio del arte. Si la filosofía se materializa a través de conceptos y la ciencia a través de functores, el arte lo hace a través de perceptos. La idea de percepto permite al autor considerar a la obra como un bloque de percepciones y sensaciones, una aglutinación que, como afirma en el Abecedario, "sobrevive a aquel que la experimenta" (Deleuze \& Parnet, 1988, p. 67). Este aspecto implica una duración y una existencia extrahumana del arte - una resistencia- que Deleuze defenderá a lo largo de muchos de sus trabajos.
} 


\section{¿Pensar es conquistar? El cine del cirujano}

Usted mirará lo que usted ve. Pero usted lo mirará plenamente. Usted intentará mirar hasta la extinción de la mirada, hasta su propia ceguedad y a través de esta deberá intentar aún mirar.

Hasta el final.

-Duras (1997, p. 44).

Para explorar el cómo del pensar del cine, tomo, en primer lugar, la lectura que hace BuckMorss (2005) de La obra de arte en la época de su reproductibilidad técnica (Benjamin, 2003). La autora elige una de las tantas líneas de comparación que utiliza Benjamin para caracterizar al cine frente a otras artes - en este caso, la diferencia entre el pintor y el operador de la cámara-. Para plantearla, Benjamin (2003) recurre a una analogía entre el mago y el cirujano:

El mago mantiene la distancia natural entre él mismo y el paciente o, con más exactitud, la reduce un poco gracias al toque de su mano y la incrementa mucho gracias a su autoridad. El cirujano procede a la inversa: reduce mucho la distancia con el paciente - al penetrar en su interior - y la incrementa solo un poco en virtud del cuidado con que su mano se mueve entre los órganos. En una palabra, a diferencia del mago (que está todavía en el médico practicante), el cirujano renuncia en el instante decisivo a ponerse de hombre a hombre frente a su enfermo; en lugar de ello se introduce operativamente en él. El mago y el cirujano se comportan, respectivamente, como el pintor y el operador de la cámara. (p. 80)

Mientras el pintor, como el mago, se mueve en un mundo distanciado de similitudes, continuidades globales y transformaciones interpretativas; el camarógrafo, como el cirujano, actúa en un universo desacralizado en el que se sumerge, parcializa, recorta, penetra. Buck-Morss (2005) sostiene que esta comparación resulta definitoria de muchas maneras para pensar la relación del cine con su contexto histórico y el modo de vínculo de los seres humanos con el arte y la política que solo puede desplegarse en sociedades capitalistas industrializadas. La autora pone en primer plano la diferencia entre el tipo de relación aurática que establece el mago con aquellos que cura y la relación del cirujano con el saber abstracto y desacralizado de la medicina occidental. El mago es poseído por fuerzas que lo conectan en un devenir cósmico durante el ritual de cura. El cirujano interviene materialmente en un cuerpo inerte, anestesiado, al que corta y reconfigura.

Manipular, cortar, penetrar, diseccionar, extraer y fragmentar son algunas operaciones que la ciencia moderna reivindica para sí y para un pensamiento que se quiere racional y objetivo. Bacon, en el Novum Organum (2011), propone que resulta necesario "penetrar en los secretos y en las entrañas de la naturaleza"” (p. 33). Descartes en el Discurso del Método (2004) sostiene que el método puede reducirse a unas cuantas reglas abstractas, que implican también dividir, considerar por partes, organizar gradualmente y, finalmente, repasar y reconstituir. El cine, con su metodología de fragmentación y construcción, puede considerarse un representante del arte de pensar de la modernidad. Su metodología de disección iniciática va mucho más allá de la toma de imágenes por medio de la cámara y se extiende primero en la configuración del guion y luego en la resignificación que supone el montaje. Es ineludible en este punto la

3 Pero si hay en el mundo hombres que tomen a pecho no atenerse a los descubrimientos antiguos y servirse de ellos, sino ir más allá; no triunfar de un adversario por la dialéctica, sino de la Naturaleza por la industria; no, en fin, tener opiniones hermosas y verosímiles, sino conocimientos ciertos y fecundos, que tales hombres, como verdaderos hijos de la ciencia se unan a nosotros, si quieren, y abandonen el vestíbulo de la naturaleza en el que solo se ven senderos mil veces practicados, para penetrar finalmente en el interior y el santuario. (Bacon, 2011, p. 35) 
referencia a Eisenstein (1999), cuando afirma que el cine es construcción de principio a fin y que el montaje como concepto es lo que lo define ${ }^{4}$.

El cine, hipertrofia del aparato óptico, puede llevar al extremo el lugar del ojo como emblema privilegiado para un modo de conocer que sitúa al sujeto del saber como dominante de la escena del conocimiento y al objeto como pasividad dominada. Produce también la llamada ilusión de realidad, que nos hace sentir que accedemos al mundo sin mediaciones, como por medio de una "ventana abierta", metáfora frecuentemente utilizada, aun cuando un complejo sistema maquínico y productivo media para la puesta en imagen final -fantasmagórica, por otra parte-. Baudry (1974) hablará de efectos ideológicos del aparato de base en el cine, para mentar la potencia significante de la máquina óptica que sitúa en un lugar súper-poderoso al ojo humano, profundizando la posibilidad que ya se había abierto con el telescopio, la perspectiva renacentista y el microscopio. Un complejo conglomerado de tecnologías construye un ojo humano-maquínico omnipotente, que supone la posibilidad de conocer y dominar al mundo en toda su grandiosidad, minuciosidad y complejidad. El autor vincula este fenómeno con el concepto de fetichismo de la mercancía, en tanto ese efecto de un conocer que se pretende omnipotente borra las condiciones maquínicas y mediadas de su producción.

Es posible filiar, entonces, el modo de narración clásico ${ }^{5}$ a la modernidad hegemónica y al modo de producción - del pensamiento- capitalista. Su pensar se entronca en una corriente que no viene heredada de las artes tradicionales, sino que está vinculada a un mundo nuevo, el mundo de la tecnología, que retoma los perceptos de una perspectiva desacralizada, maquinizada y signada por la conjunción entre la razón como facultad rectora del conocimiento y la ciencia como producto de ese saber.

Entonces, ¿cómo piensa el cine?, ¿qué le propone a la filosofía y a su enseñanza en ese pensar? En esta descripción se llevó al paroxismo un afán de conocer a través de las figuras clásicas de un sujeto y un objeto: un sujeto activo -intelectual- y un objeto pasivo - material- Las operaciones del pensamiento se determinan al calar más y más profundamente en los misterios del objeto, con la esperanza final de dejarlo vacío de significación, despojado de misterio. Insisto en las palabras sonsacar, fragmentar, manipular, atravesar, penetrar, conquistar. Ellas resuenan potenciadas en un contexto de epistemologías feministas y decoloniales que nos reclaman sospechar de la universalización de esta concepción específica del pensar como "pensar humano". En nuestro contexto

4 Para Eisenstein (1988, 1999), como buen hegeliano, la verdad del montaje debe trascender la disección y suma de partes, para generar un salto dialéctico de sentido, lo patético. Esta concepción enrola a Eisenstein como creador y pensador en el tipo de obras que consideraré en el próximo apartado. Para una profundización en el vínculo entre Eisenstein y la enseñanza de la filosofía se puede consultar Primera secuencia: el cine de ficción en la enseñanza de la filosofia (Galazzi, 2012).

5 Las clasificaciones y agrupaciones resultan, indudablemente, siempre injustas y demasiado generales. En los primeros tres apartados acudo a estas generalizaciones como una forma de acercarme a ciertas posibilidades del pensar del cine, pero prevengo a partir de ahora respecto de la amplitud y generalidad de los tres criterios en que agrupo algunas obras cinematográficas. En la tripartición solapo dos fuentes antecedentes: la primera es la tradicional clasificación basada en la narrativa que realiza Bordwell (1996), en la que se distingue entre narración clásica y narración de arte y ensayo —además de otras que no se tomaron en cuenta aquí-. La segunda es la discriminación que propone Deleuze $(1984,1986)$ entre cine de la imagen-movimiento y de la imagen-tiempo. Ambas clasificaciones incorporan elementos históricos. En el caso de Deleuze, se periodiza la etapa que va de los comienzos del cine hasta el fin de la Primera Guerra Mundial para la imagen-movimiento y el cine de posguerra hasta el presente para la imagen-tiempo. En el caso de Bordwell, los años 50 son el quiebre para el surgimiento del cine de arte y ensayo. Sin embargo, ambas clasificaciones están centradas en aspectos diacrónico-conceptuales, como la diferenciación de los tipos de narración, en el caso de Bordwell, o el tipo de construcción de las imágenes, en el caso de Deleuze. Propongo una tripartición que se nutre de estos antecedentes, pero ensaya un recorrido propio interesado en vincularlos con la enseñanza de la filosofía. 
histórico, ya tiene respuesta la idea de que este modo de pensar detenta una hegemonía al imponerse como falso universal, en tanto deja de lado pensares otros, considerados femeninos, infantiles o primitivos. Para tomar un ejemplo, podemos nombrar a los muiscas, un pueblo pensador, según Rozo-Gauta (1997), ya que su cosmogonía se basaba en sostener y regenerar el universo a través de los pensamientos. Por ello comprendían que "el mundo es uno, una globalidad, un conjunto de cosas, eventos, seres y acciones correlacionados entre sí en la ambientación de un pensamiento totalizante" (p. 65). En esta cultura, el pensar es valorado como una puesta en conexión que vincula de modo orgánico, sin fragmentar, ni especializar los saberes. Es frecuente encontrar en los pueblos originarios de América algún tipo de concepción del pensar conectiva y totalizante, más que analítica y fragmentaria. Así, el pensar muy otro del cine - que podríamos llamar de la conquista o de la capturaparece alejarse de una mirada totalizadora del mundo. Responde a una fruición escópica que individualiza y centraliza la mirada en el ojo; y el ojo en el sujeto, lo cual hace del fragmento y la especialidad el centro del conocer.

¿Con qué educación dialoga este modo del pensar cinematográfico? Efectivamente la compartimentación escolar del tiempo, del espacio y de las disciplinas es hermana de este modo de pensamiento. Hoy en día sería una pedagogía tecnicista, de completo correlato entre evaluación y objetivos, entre observación y aprendizaje, la que se encuadraría en este tipo de perspectiva; una pedagogía tecnicista, de cirugía, que pueda hacer del cine también un objeto a diseccionar, una superficie a sonsacar y analizar, para mejor conocer y profundizar fuentes filosóficas que serán retomadas del mismo modo. Desde esta perspectiva, el cine y el resto de las artes resultan instrumentalizados, ya que se borra la potencialidad lúdica y creativa que puede tener nuestro vínculo con el arte. $\mathrm{Si}$, por ejemplo, la literatura se puede utilizar en clase como una superficie para marcar en una página sustantivos y adjetivos, también una película puede utilizarse como un mero medio para analizar un texto filosófico.

Esta perspectiva filosófico-pedagógica se vincula, además, con lo que podríamos llamar filosofía hegemónica, construcción académica preocupada por delimitar los parámetros del pensar, al considerarlos medibles y cuantificables en función de organizar, clasificar, establecer jerarquías y construir rankings de investigaciones e investigadorxs. Este pensar -al que se le ha decretado la muerte y del que se ha denunciado la esterilidad tantas veces- adquiere fuerza y vitalidad diariamente en la filosofía, en la educación y en el cine. Este último, según nuestra descripción, es el arte que puede llevar hasta un extremo muy palpable, visible y audible este modo de vinculación con el mundo. También podría dialogar con una pedagogía que quiera mostrar sus características y límites, sus promesas y engaños. La razón instrumental cubre como un manto toda nuestra configuración de lo real y permite establecer un continuo entre la ciencia, el cine, el pensamiento y la filosofía. Por lo tanto, nunca está de más adentrarnos en las características y problemas que los constituyen. Pero, sin embargo...

\section{¿Pensar es ser afectadx? El cine de la intensidad}

Quería decirle: el cine cree poder consignar lo que hace usted en este momento. Pero usted, desde donde vaya a estar, sea donde sea, en concordancia con la arena, o el viento, o el mar, o la pared, o el pájaro, o el perro, se dará usted cuenta de que el cine no puede. -Duras (1997, p. 47).

La cámara cinematográfica más común captura 24 fotogramas por segundo. 24 fotos fijas que generan la ilusión - y solo la ilusión - de la realidad. Entre los fotogramas, subsiste el 
espacio vacío de una incertidumbre sobre lo real. Esta falta en la captación de la totalidad del tiempo y el espacio desde los primeros tiempos se develó como inquietante, como símbolo de otras discontinuidades que luego se acentuarían en el montaje, en la reconstrucción ficcional del mundo para ser filmado, en la fantasía mágica de un Meliés. El aparato captura, a la vez que deja pasar; inventa, tanto como disecciona.

Como afirma Zambrano (2007) "un dato sensorial supone y lleva consigo un mundo, quizás el mundo todo" (p. 58). La conjunción del sonido, la imagen, la proyección y el cuerpo que percibe no es igual a la suma de las partes. Para la filósofa no nos encontramos con percepciones simples, sino con constructos complejos de "verde lanoso" o de "rojo sangre". La imagen-movimiento o la imagen-tiempo constituyen conglomerados de elementos con sentido completo. Los perceptos disparan el pensamiento a estratos que no pueden ser calculados de antemano.

Si Baudry (1974) ve cómo indefectiblemente el aparato de base por el cual se produce el cine es ideólógico, Deleuze $(1984,1986)$ y Benjamin (2003) considerarán que también hay algo más. Anclada en la inmanencia, nuestra condición consiste en llegar a la historia "por la mitad". Estamos inmersxs en una realidad de máquinas capitalistas para las que no hay afuera desde el cual mirar sin condicionamientos y sin mácula. Entonces, es en la inmanencia donde se despliegan las capturas y las fugas, las conquistas y las resistencias. En ese sentido, el cine parece encerrar también la promesa de un pensar otro, de un modo de conocer que se abre a la incertidumbre, a la caricia, al espanto. Si hay un pensar cinematográfico de la conquista y de la captura, también hay uno de la intensidad y del desgarro (Duras, 1997).

El cine moderno ha explorado vías de enunciación que recusan, deconstruyen, evidencian o se alejan de la apariencia compacta y fuertemente ideológica del cine narrativo clásico. Al montaje como eje rector lo siguen otros caminos que exploran un cine del plano, de la continuidad o de la discontinuidad extrema, de la luz, del sonido, de la poesía, incluso de la pantalla en blanco o en negro. Este cine, de algún modo, ya estaba ahí: en la contemplación de las brumas de Odessa, dice Deleuze (1986), "ya estaba la posibilidad de la fractura del pensamiento dialéctico" (p. 226). En el delirio de Alice Guy Blaché tenemos ya los elementos para sostener que siempre hay algo que se fuga en el pensar, que disloca el sentido y lo desestructura.

El cine moderno será el que profundice en estos caminos. Utilizará múltiples estrategias para inventar mundos que trastocan nuestras formas de percepción e inauguran otras derivas posibles para el pensamiento. Las variantes actualmente parecen infinitas: desde el gesto de Godard o de Faroki de llevar al paroxismo la fragmentación y la mostración de las estrategias de un conocimiento racional y analítico, hasta las experimentaciones de Won Kar Wai con la luz y el sonido para crear un universo de sensaciones; desde el estudio de las capas superpuestas de sentido en la profundidad de campo que realiza Welles, hasta las búsquedas de realización de una poesía fílmica por parte de Tarkovsky o Duras.

Este pensamiento abandona la ilusión de la totalidad, para situar al cine desde la perspectiva de la fractura. Deleuze (1986) propone que el sujeto de este cine es "el idiota", al mencionar el personaje de Dostoyevski (2017): un sujeto que está paralizado, que observa la intensidad del mundo sin tener una respuesta prefijada o automatizada para dar; un sujeto que, por ello mismo, es pensador, ya que ningún sentido común, ningún cliché, le permite 
dar una respuesta automática a los estímulos que permanentemente lo asedian; muy por el contrario, a quien el mundo se le presenta como hostil, o como enigmático.

Este sujeto del pensamiento está muy lejos del lugar del sabio, de una posición de sujeto "pura" o "incondicionada", como afirma Longino (1998). Su pensar es un no pensar todavía - para decirlo con Heidegger (2005) - o una promesa del pensar como un viento que todo lo disuelve - para decirlo con Arendt (1995)_. Es un pensamiento de intensidad que, como proponen las epistemologías feministas, no se relaciona con su objeto al modo de la conquista y la reducción. Se trata más bien de un vínculo empático u horrorizado, nunca indiferente; un vínculo que tiene que ver también con la necesidad de la acción, de clamar por otros mundos, de salir de la asfixiante ordenación desigual, jerárquica e injusta de los constructos sociales que nos rodean; un conocimiento que es más bien amor por el pensar, que acaricia el objeto con todos los sentidos, los recorre en su superficie. Ya no penetra y disecciona, sino que fusiona, palpa, huele, se deja disolver y transformar por el objeto. Es un cine de la experiencia vivida, más que de experimentación científica.

Una hermandad posible se construye aquí con todas aquellas filosofías y pedagogías "menores" (Gallo, 2003) que intentan también este modo de pensamiento. Nuevamente, las pedagogías feministas, decoloniales, las estrategias de filosofía con niñxs o las filosofías del acontecimiento se vinculan con este cine también de modo amoroso para generar pensares posibles en el aula. El esfuerzo aquí es el mismo que con los textos y los temas: no caer en el endiosamiento de los estrellatos; no centrarnos solo en el cine hegemónico; explorar las filmografías latinoamericanas, africanas, asiáticas y de todos los pueblos y autores que enuncien desde un lugar otro; $y$ tener muy en cuenta a las directoras a la hora de seleccionar.

Este cine en el aula tiene la potencia que todo "pensar otro" abre para la filosofía, ya que nos deja perplejxs, nos genera preguntas de contenido y de forma, de lenguaje: ¿por qué lo dijo de este modo? ¿Por qué me resulta raro lo que veo? ¿Para qué decir de esta manera? ¿Qué estructuras tiene naturalizadas mi mirada? Creo que estas preguntas se pueden producir intensamente con el acercamiento en el aula al cine de arte y ensayo, y que son provocaciones para motivar otras miradas, ya no solo en el ámbito del cine, sino también en el ámbito del conocimiento científico, de la política y de la filosofía. Así, como siempre, resulta provechoso encontrarnos con ese cine que en principio nos resulta ajeno, enigmático, molesto o indescifrable.

\section{¿Pensar es hacer? La vida en imágenes}

Que es usted, usted lo olvidará.

Creo que se puede conseguir.

Usted olvidará también que es la cámara. -Duras (1997, p. 43).

Hablar hoy de fotogramas y segundos para referirnos al cine es casi hacerlo con metáforas. Del video a la imagen digital, el cine adquiere una nueva ontología que se desliza del fotograma al bite, al pixel. Se diseñan imágenes que son conglomerados, construcciones

$6 \quad$ Uso "menor" en tanto concepto. Tomo la construcción que realizan Deleuze y Guattari en Kafka, para una literatura menor (1978). Allí "menor" hace referencia a una posición de enunciación marginal, que utiliza a la vez que reconfigura la lengua hegemónica. Implica un tipo de subjetivación marginal, desterritorializante, colectiva y, por lo tanto, con potencial político. 
infinitesimales, que tienen la posibilidad de desarmarse y rearmarse, incluso de realizarse completamente en entornos digitales.

Para abordar el tipo de pensamiento que supone la imagen digital, retomo un señalamiento de Dubois (2001). Él propone que de la pintura a la imagen digital hay una progresiva transformación que implica dos aspectos: la desmaterialización de la imagen y la independencia del objeto. Observa que la pintura se presenta como un objeto con espesor, textura, peso, que se aliviana en la fotografía y se fantasmagoriza en el cine, pero aún se puede detener en el fotograma como soporte. La imagen digital, en cambio, es un constante flujo: “¿Qué es exactamente una imagen electrónica? Es varias cosas, pero nunca realmente una imagen. Es solamente un proceso" (p. 27). Por otra parte, respecto de la dependencia del objeto, resulta evidente que la imagen digital puede desarrollar mundos enteramente virtuales, que convierten al objeto en un puro algoritmo.

Así, desde el videoarte y la instalación, hasta la intensa proliferación de imágenes con pretensión artística y sin ella de las redes sociales, estamos inmersxs en un mundo donde algo que nació con el nombre de cine - y hoy tiene múltiples nombres- es omnipresente en nuestras vidas y nos construye como sujetos de unas nuevas maneras. También nosotrxs nos desmaterializamos, nos virtualizamos, nos subjetivamos como procesos más que sucesos únicos y nos fragmentamos a través de nuestros avatares virtuales en las redes sociales. Tal como afirmaba Deleuze (1995), en los nuevos entornos nos volvemos dividuos, con aspectos dispersos y fragmentarios que se despliegan en un flujo que no respeta los principios de identidad, no contradicción, tercero excluido. Por ello, podemos decir, hoy más que nunca, que pensar el cine, con el cine, en el cine, por el cine, es pensarnos y a nuestro entorno sociocultural, político y económico. Es una herramienta para abordar nuestro mundo.

Hoy, particularmente, cuando el cine ha llevado al paroxismo su masificación y su posibilidad de ser apropiado por cualquiera ${ }^{7}$, para pensar el cine y pensarnos a través de él, es muy importante, además de mirar películas o series de un formato ya cásico, analizar los audiovisuales amateurs que subimos a las redes sociales, que intercambiamos, que valoramos o criticamos, y producir audiovisuales en las aulas. Considerar las producciones para el espacio "virtual" como menos "reales" que nuestra vida cotidiana, como algo que queda fuera del aula, solo puede ser hoy un reflejo de otro tiempo, donde no forjábamos nuestra identidad en esos espacios.

Por otra parte, la realización de audiovisuales que dialoguen con las redes sociales abre quizá la posibilidad de atravesar las distinciones privado/público, personal/político, individual/social, tan caras a los principios ilustrados modernos que organizan el espacio escolar y tan discutidas por las perspectivas críticas en educación y las nuevas pedagogías. Un sujeto permeado por la experiencia — atravesado por el género, por la sexualidad, por la vida cotidiana y por los entramados de sentido que se construyen en espacios reales y virtuales - abre otros mundos para la filosofía, sobre todo en la escuela media, donde las temáticas, las modalidades de trabajo y los tipos de discusión son también diferentes respecto de los demarcados por el canon rígido heredado de la historia de la filosofía. Es también nuestro desafío descubrir, con el cine digital y su omnipresencia en la vida

7 Badiou (2004) afirma, en consonancia con Benjamin, que el cine, en tanto arte de masas, es un arte democrático, un arte en que cualquiera puede ser un experto. Este carácter democrático, y más aún, el carácter antiaristocrático del cine ha logrado transformar la relación de las personas con el arte en general 
cotidiana, nuevos temas y problemas filosóficos que atraviesan nuestro presente.

\section{Dividuaciones maquínicas. Los fundamentos de un modo de trabajo}

Usted mirará a todos los espectadores de la sala uno por uno y cada uno en sí. Recuerde usted bien esto: la sala es por sí sola el mundo entero y también lo es usted, por usted solo. No olvide nunca -Duras (1997, p. 57).

Sería muy limitado nuestro trabajo si considerásemos que el cine es un recurso instrumental para explicar sistemas clásicos de la historia de la filosofía. Si hay una riqueza en incorporarlo en las tres dimensiones que señalé - la dimensión de la conquista, la dimensión de la intensidad y la dimensión de la autoconstrucción cinematográfica, y seguramente en muchas otras más que es posible pensar-, es porque el poder de su pensamiento puede transformarnos, a nosotrxs y a la filosofía. En ese sentido, trabajar con el cine es mucho más que un recurso; es una oportunidad para convertir nuestras clases en experiencias filosóficas.

En esta última parte me centraré en algunos fundamentos de la necesidad de hacer audiovisuales en el aula de filosofía, vinculados a la dimensión de la autoconstrucción cinematográfica. Si las imágenes actualmente son una dimensión importante de la construcción identitaria de aspectos dividuales ${ }^{8}$ que nos atraviesan, es un desafío explorar estas derivas en nuestras clases. Sobre todo, para incorporar a las clases aspectos de la vida de lxs jóvenes que es posible resulten más extraños a generaciones anteriores. Schwarzböck (2017) afirma:

Una vez que el espectador aprende, viendo películas, a identificarse con la cámara, no es más el mismo sujeto que en los siglos sin cine. La mirada humana deja de ser, definitivamente, lo mismo que los ojos. La humanidad se prepara para vivir en un mundo controlado por cámaras. (p. 82)

En este contexto, siempre resulta contrafáctico preguntarnos cómo sería la vida si no hubiese imágenes puestas en circulación, redes sociales y autoconstitución identitaria a partir de ellas. En el espacio público y privado, una dimensión de nuestra experiencia incluye la presencia de la mirada de la cámara. A diferencia del protagonista de The Truman Show (Weir \& Rudin, 1998) no tenemos un afuera adonde escaparnos. La mirada maquínica nos constituye y nos acompaña. Moldea nuestra percepción, nuestra acción y nuestros deseos, organizados en parte por y para la cámara. Incluso nuestras palabras, sobre todo en las redes sociales, están permeadas por un ojo maquínico preeminentemente visual, que se constituye en el parámetro a partir del cual organizamos la comunicación, los afectos y la percepción.

Si en las sociedades disciplinarias foucaultianas lo que se introyecta es la mirada del padre -Dios o razón- que vigila las conductas y reprime todo aquello que se desvíe de los parámetros normalizadores de la disciplina, en las sociedades de control deleuzianas la mirada de las cámaras proliferantes propone otras subjetivaciones. Si pensamos, por ejemplo, cómo serán visionadas las imágenes de una golpiza realizada por sus propios

8 El concepto de dividuo permite comprender la individuación como un proceso que no culmina ni aspira a un Yo o Sujeto - con mayúscula - singular y único, sino como un recorrido multifacético y plural, en el que la diferencia se produce en el desarrollo de líneas o facetas colectivas. En las redes sociales, en las familias, en el trabajo, en la escuela, en el grupo de pares, etc., se desarrollan aspectos dividuales que ya no aspiran necesariamente a una coherencia u organicidad. 
perpetradores - como es común observar amplificadas en los medios de comunicación cuando terminan en una muerte, por ejemplo-, resulta evidente que no se filmaron para ser observadas en soledad, mucho menos para documentar la crueldad y expiar la culpa. Más bien, podemos adelantar una circulación por redes sociales, festejos o críticas, discusiones, pero sobre todo circulación, viralización, consumo. Poco importa si el efecto es de construcción de poderío y violencia, de repulsión y rechazo, o incluso si fueran rotuladas como imágenes prohibidas y retiradas de las redes. Las imágenes se hacen importantes en la medida en que tienen likes y visualizaciones, o si son prohibidas y pasan a convertirse por un tiempo en objeto de culto. En tanto las imágenes circulan, resultan atractivas y su ciclo se alarga, dando vida a las dividuaciones. Schwarzböck (2017) señala que "quien exhibe su intimidad no la exhibe porque la considera extraordinaria, sino porque considera que ninguna intimidad es extraordinaria, tampoco la suya. Nadie necesita nada extraordinario para poder exhibirse" (p. 155).

El audiovisual ya no es el lugar de lo extraordinario; al contrario, es el lugar de lo común, de la vida, donde se realiza lo cotidiano y se performa la identidad. Por eso, cuando se apaga el ciclo de circulación, resulta necesario alimentar esa vida y esa cotidianidad con nuevas imágenes, para conjurar el riesgo de ser invisible. En ese sentido, la necesidad de producción de imágenes compele a la producción de acontecimientos retratables y el pensamiento se transforma en una máquina de producción de y para la circulación de imágenes. El riesgo de la invisibilidad no puede minimizarse. Es el meollo de la identidad dividual lo que se juega en esas estrategias de aparición y desaparición de los yos — personales o colectivos-. En ese sentido, es necesario explorar los efectos de las imágenes en nuestras vidas.

\section{Crear para pensar. La realización de videominutos en el aula}

Fue entonces cuando me dije por qué no. Por qué no hacer una película. Escribir sería demasiado de ahora en adelante. Por qué no una película. -Duras (1997, p. 55).

Con los fundamentos ya esbozados, es posible desarrollar muchas estrategias de trabajo diferentes para pensar en las aulas de filosofía. En este caso, propongo un taller de reflexión filosófica a partir de la realización de videominutos. El taller está diseñado en varias partes, que describiré brevemente. Usaré como ejemplo las versiones de un taller que desarrollé en el seminario que dio origen a este texto.

\section{Introducción y encuadre de la tarea}

El inicio de la tarea, además de introducir los fundamentos del taller y explicar sus pasos, debería enfocarse en proponer y mostrar alguna herramienta del lenguaje del cine, seleccionada previamente, con la que se va a trabajar para realizar los videominutos. En las versiones de este taller que realicé, propuse el trabajo con dos herramientas: el plano secuencia y la secuencia de montaje de fotos fijas. El objetivo de proponer dos herramientas concretas de lenguaje con las que trabajar - $\mathrm{o}$ al menos una de ellas - consiste en acotar las dificultades que puedan aparecer en la realización de los videos y dar un encuadre claro y preciso al lenguaje audiovisual, para dejar más abierto y difuso el aspecto problemáticofilosófico.

Es necesario tener en cuenta que, si bien es muy común que lxs estudiantes tengan un 
acceso muy facilitado e intuitivo a las herramientas audiovisuales, no es tan común que conozcan en qué consiste cada estrategia lingüística del cine o que puedan planificar de antemano los recursos audiovisuales que se utilizarán. Por ello, resulta importante dedicar un tiempo a explicar y ejemplificar lo que se espera. Este encuadre claro al inicio del taller resulta fundamental para no interponer obstáculos luego en las realizaciones. En este caso, la elección recayó sobre estas dos estrategias porque resultan interesantes de implementar y accesibles para su realización. En el caso del plano secuencia, el mayor desafío se encuentra en su planificación: disponer un escenario de objetos, imágenes, pequeñas escenas, incluso música o sonidos en vivo, para ejecutar el plano sin cortes. En el caso de la secuencia de montaje de imágenes fijas, la realización puede ser menos planificada. El mayor desafío consistirá en ordenar la secuencia, elegir palabras o imágenes para superponer a las tomas. En fin, el montaje será la clave de su realización. En cuanto a la ejemplificación de ambos procedimientos, elegí utilizar el inicio de La ventana indiscreta (Hitchcock, 1954) para el plano secuencia y el inicio de Letter to Jane (Gorin \& Godard, 1972) para la secuencia de montaje con imágenes fijas.

\section{Momento de realización}

Para la realización de los videominutos, se conformaron pequeños grupos. En el espacio del aula se dispusieron dos sectores con insumos para el trabajo. Hubo un sector con sobres que contenían grupos de fragmentos filosóficos divididos por temas. La selección de textos dependerá de cada implementación del taller, sobre todo si el curso en que se realiza tiene alguna temática particular. En este caso, como el taller fue dictado a docentes de filosofía para que pudieran utilizarlo en sus propias propuestas de enseñanza, seleccioné grupos de fragmentos muy variados y los agrupé por temáticas en cada sobre -el conocimiento, el aprender, lo humano, la razón, la mujer-. En la selección, procuré que los fragmentos dialogaran entre sí, para abrir diferentes posibilidades. Hubo fragmentos contrapuestos, pero también abiertos en diversas direcciones. El objetivo es que el grupo los utilice como disparador para las imágenes que va a diseñar, sin que pauten un sentido unívoco. Además, intenté que resultara casi imposible retomar todos los fragmentos en el videominuto, para que el grupo tuviera que construir un pensamiento propio sobre el tema. En todo caso, deberían funcionar como llaves, como herramientas, como inicios de la discusión, más que como argumentación a reponer o a replicar. Los fragmentos son, entonces, el grupo principal de insumos que se utiliza en el taller. En este caso se propuso una oferta variada de temas.

El segundo grupo de elementos que se dispuso en el aula fueron reproducciones impresas de pinturas y fotografías. Se dispusieron más de 60 imágenes, seleccionadas según diversos criterios, entre ellos: los ejes temáticos, la variedad de las técnicas y estilos, la diversidad de género de lxs artistas, la diversidad de geografías y contextos temporales en que se crearon las imágenes, etc.

Las imágenes se pensaron con el objetivo de que pudiesen contar con un repertorio amplio de elementos visuales a la hora de crear las secuencias. No se propusieron como de uso obligatorio. Algunxs estudiantes no las utilizaron. Filmaron secuencias en el aula, los pasillos, el campus de la universidad, etc. Se puede prescindir por completo de estas imágenes si lxs estudiantes realizan este taller en varias clases y crean sus videos fuera del 
espacio del aula, en sus computadoras, al recurrir a secuencias creadas por ellxs o editadas desde fuentes previas. En este caso, el taller fue pensado para realizarse en un tiempo breve, que no permitía siquiera hacer una búsqueda exhaustiva de imágenes por internet para incorporar a las secuencias, ni alejarse para filmar del lugar donde se realizaba el taller. En ese contexto, es importante abrir la posibilidad estética para poder ampliar el repertorio de imágenes de los videos.

Cada grupo tuvo una consigna - crear un videominuto al realizar una secuencia de montaje de imágenes fijas o un plano secuencia-, unos insumos -imágenes y textospara cumplir esta consigna y un tiempo para planificar, crear y editar su audiovisual ${ }^{9}$. En este caso, la herramienta que se utilizó fueron los celulares de lxs estudiantes y una aplicación llamada InShot, donde fácilmente se pueden montar imágenes, insertar textos, agregar sonidos y música, así como procesar las imágenes para compartir en redes sociales ${ }^{10}$. Se utilizó un grupo cerrado de Facebook para compartir los videominutos.

\section{Cierre reflexivo}

El momento final del taller, cierre de los trabajos, es quizá el momento central. Allí resulta fundamental poder visualizar en grupo los resultados del trabajo de todxs y discutirlos con tiempo. Este momento permitirá intercambiar grupalmente desde diferentes ejes de discusión, que pueden desplegarse en diversos pasos. El primero es el intercambio con lxs estudiantes respecto de lo que quisieron hacer, el grado de realización que lograron, la intención que tenían al contar. El segundo es el análisis respecto de qué vieron los demás, qué encontraron en el audiovisual, qué abrió a la discusión. En ambos casos, habría un doble aspecto para revisar: uno el vinculado a la temática propia del audiovisual y otro vinculado al modo en que producimos y visualizamos audiovisuales breves que se comparten en redes sociales. Se podrían abrir preguntas como: ¿Qué les dice este audiovisual del grupo de compañerxs que lo realizó? ¿Lo postearían en su muro de Facebook, Instagram, etc.? Si lo hicieran, ¿qué diría de ustedes este audiovisual? ¿Qué querrían transmitir a otrxs? Si no lo hicieran, ¿cuáles serían las razones?

En fin, el objetivo de la actividad es que los videominutos realizados por los grupos abran una reflexión filosófico-temática — a través de la problemática abordada por el corto- y a una dimensión de análisis estético, en función de considerar el modo en que configuramos nuestra experiencia sensible del mundo a través de la construcción audiovisual, el modo en que nos posicionamos perceptivamente en un mundo atravesado por lo virtual y el modo en que componemos el pensamiento en imágenes.

\section{El cine, una experiencia}

No intente comprender ese fenómeno fotográfico, la vida. -Duras (1997, p. 58).

Volviendo a las tesis de Schwarzböck (2017), el cine durante los siglos XX y XXI, pensado como construcción audiovisual, se ha constituido en una pedagogía. La construcción formal

\footnotetext{
9 Estos pueden variar según la duración y la orientación del curso. En un curso escolar puede realizarse en el transcurso de toda una unidad de trabajo, por ejemplo.

10 Por supuesto, los recursos pueden ser variados. Si hay netbooks, tabletas o PC disponibles en la institución o las tienen lxs estudiantes en sus casas, se pueden utilizar múltiples programas que tienen un acceso intuitivo y simple. En las versiones que realizamos del taller, contamos con aulas de informática con computadoras que tenían instalado el programa Avidemux.
} 
produce mundo, vidas, identidades. Ordena nuestro modo de percibir, de pensar, de ser. Por ello, reflexionar acerca de los procedimientos de construcción, circulación y visionado de imágenes y sonidos resulta fundamental para poder comprendernos a nosotrxs mismxs y a nuestro entorno socio-político-cultural.

La filosofía en la educación, sobre todo en el espacio de la escuela primaria y media, está siempre desafiada a resignificarse. Cada vez resulta más evidente que una construcción enciclopédica delos contenidos, donde se estudian sin solución de continuidad los principales "nombres" de filósofxs y algunas ideas principales no satisface siquiera el objetivo de introducir contenidos de cultura general. Luego de la evaluación, estos saberes memorizados y repetidos se vuelven descartables. Resultan, en cambio, saberes fundamentales, cuando la filosofía logra calar en la experiencia, en los afectos y en los cuerpos de quienes están aprendiendo. Estas situaciones educativas abren una puerta para la filosofía en la vida de lxs estudiantes que lxs acompaña luego en diferentes momentos, lo cual permite la pregunta, la interrogación y el examen de sí mismxs y del entorno.

Volver a la filosofía una experiencia significativa en el aula es una búsqueda que implica constituirnos, nosotrxs como docentes y nuestrxs estudiantes como grupo, en un colectivo filosofante que puede problematizar el entorno y preguntarse acerca de sí mismo, de la vida cotidiana, de las experiencias que vivimos en espacios reales y virtuales. Hacer de la vida un objeto de examen es, quizá, uno de los primeros objetivos que se planteó la filosofía con Sócrates y, sin lugar a dudas, siempre estamos de alguna manera detrás de esa búsqueda cuando intentamos enseñar filosofía. En nuestro tiempo, visionar, analizar y realizar audiovisuales puede ser un buen camino para hacernos la pregunta por nosotrxs mismxs $y$, por qué no, para ensayar también algunas respuestas.

\section{Referencias}

Arendt, H. (1995). El pensar y las reflexiones morales. En De la historia a la acción (pp. 109137). Paidós.

Bacon, F. (2011). La gran restauración (Novum organum). Tecnos.

Badiou, A. (2004). El cine como experimentación filosófica. En G. Yoel (coord.), Pensar el cine 1. Imagen, ética y filosofía (pp. 23-90). Bordes-Manantial.

Baudry, J. (1974). Cine: los efectos ideológicos producidos por el aparato de base. Lenguajes: Revista de Lingüística y Semiología, 1(2), 53-67.

Benjamin, W. (2003). La obra de arte en la época de su reproductibilidad técnica. Ítaca.

Bordwell, D. (1996). La narración en el cine de ficción. Paidós.

Buck-Morss, S. (2005). Walter Benjamin. Escritor revolucionario. Interzona.

Deleuze, G. (1984). La imagen-movimiento. Estudios sobre cine 1. Paidós.

Deleuze, G. (1986). La imagen-tiempo. Estudios sobre cine 2. Paidós.

Deleuze, G. (1995). Conversaciones. 1972-1990. Pre-Textos.

Deleuze, G., \& Guattari, F. (1978). Kafka. Por una literatura menor. Era. 
Deleuze, G., \& Parnet, C. (1988). El abecedario. Escafandra.

Descartes, R. (2004). Discurso del método. Colihue.

Dostoyevski, F. (2017). El idiota. Ex Libris.

Dubois, P. (2001). Video, cine, Godard. Libros del Rojas.

Duras, M. (1997). El hombre atlántico. En Duras, M., El cine del desgarro (pp. 41-64). Banda Aparte.

Eisenstein, S. (1998). Reflexiones de un cineasta. Lumen.

Eisenstein, S. (1999). Aproximación dialéctica a la forma del cine. En Eisenstein, S., La forma del cine (pp. 48-64). Siglo XXI Editores.

Galazzi, L. (2012). Mirando conceptos: el cine en la enseñanza de la filosofía. Libros del Zorzal.

Gallo, S. (2003). Deleuze \& Educação. Autêntica.

Gorin, J-P., \& Godard, J-L. (1972). Letter to Jane [Película]. Grupo Dziga Vertov.

Heidegger, M. (2005). ¿Qué significa pensar? Trotta.

Hitchcock, A. (1954). Rear window (La ventana indiscreta) [Película]. Rudin/Paramount.

Longino, H. (1998). Sujetos, poder y conocimiento: descripción y prescripción en las teorías feministas de la ciencia. Feminari, 11(21), 21-29.

Rozo-Gauta, J. (1997). Espacio y tiempo entre los muiscas. El Búho.

Schwarzböck, S. (2017). Los monstruos más fríos. Estética después del cine. Mar Dulce.

Weir, P., \& Rudin, S. (1998). The Truman Show [Película]. Rudin/Paramount.

Zambrano, M. (2007). Filosofía y educación. Manuscritos. Ágora. 